\title{
Breast phyllodes tumor: A review of literature and a single center retrospective series analysis
}

\author{
Gianluca Spitaleri $^{\mathrm{a}, *, 1}$, Antonio Toesca ${ }^{\mathrm{b}, 1}$, Edoardo Botteri ${ }^{\mathrm{c}}$, Luca Bottiglieri ${ }^{\mathrm{d}}$,
} Nicole Rotmensz ${ }^{\mathrm{c}}$, Sabrina Boselli ${ }^{\mathrm{a}}$, Claudia Sangalli ${ }^{\mathrm{b}}$, Chiara Catania ${ }^{\mathrm{a}}$, Francesca Toffalorio ${ }^{\mathrm{a}}$, Cristina Noberasco ${ }^{\mathrm{a}}$, Angelo Delmonte ${ }^{\mathrm{a}}$, Alberto Luini ${ }^{\mathrm{b}}$, Paolo Veronesi ${ }^{\mathrm{b}, \mathrm{e}}$, Marco Colleoni ${ }^{a}$, Giuseppe Viale ${ }^{\mathrm{d}, \mathrm{e}}$, Stefano Zurrida ${ }^{\mathrm{b}, \mathrm{e}}$, Aron Goldhirsch ${ }^{\mathrm{a}}$, Umberto Veronesi ${ }^{b}$, Tommaso De Pas ${ }^{a}$

\author{
${ }^{a}$ Department of Medicine, European Institute of Oncology, Milan, Italy \\ ${ }^{\mathrm{b}}$ Division of Breast Surgery, European Institute of Oncology, Milan, Italy \\ ${ }^{c}$ Division of Epidemiology and Biostatistics, Tumor Registry, European Institute of Oncology, Milan, Italy \\ ${ }^{\mathrm{d}}$ Division of Pathology, European Institute of Oncology, Milan, Italy \\ ${ }^{\mathrm{e}}$ University of Milan School of Medicine, Italy
}

Accepted 12 June 2013

\section{Contents}

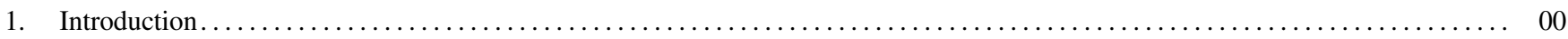

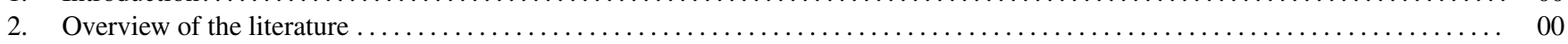

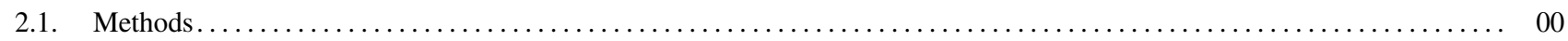

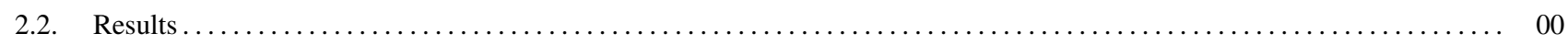

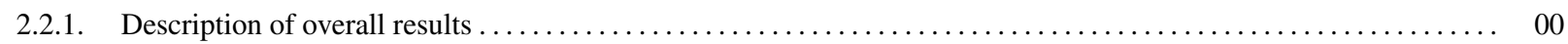

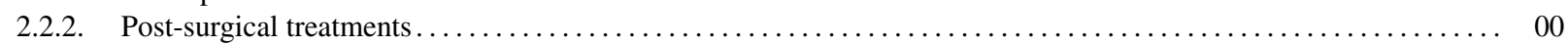

2.2.3. Biomarkers involved on tumor progression from fibroadenoma to malignant phyllodes tumor $\ldots \ldots \ldots \ldots \ldots$

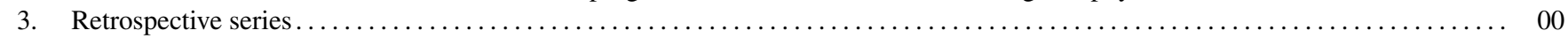

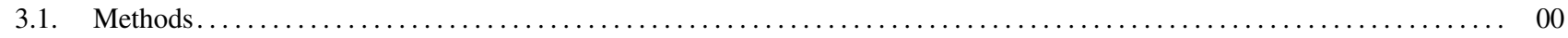

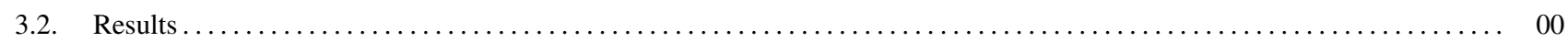

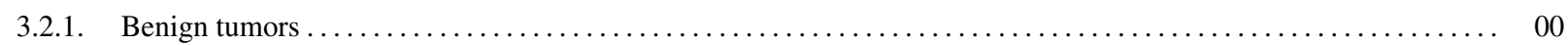

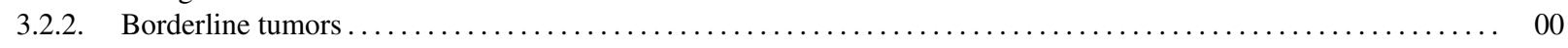

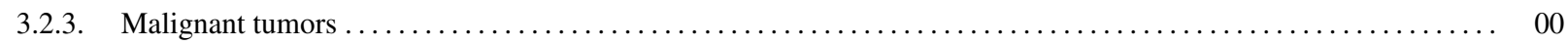

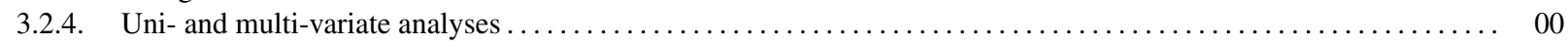

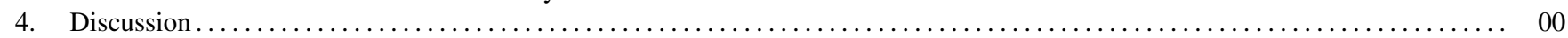

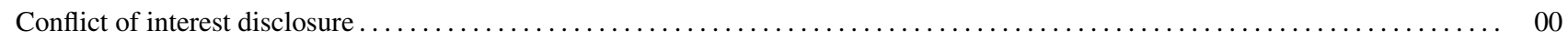



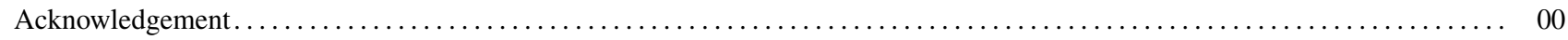

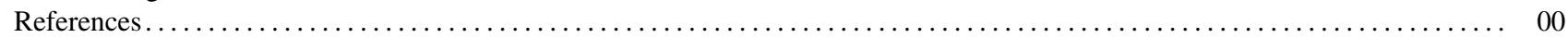

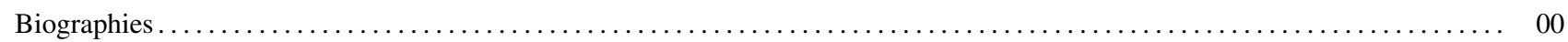

\begin{abstract}
Purpose: Complete surgical resection is the standard treatment for localized breast phyllodes tumors. Post-surgical treatments are still a matter of debate. We carried out an overview of the literature to investigate the clinical outcome of patients with phyllodes tumor. A retrospective analysis of mono-institutional series has been included as well.
\end{abstract}

\footnotetext{
* Corresponding author at: Division of New Drug Development and Clinical Pharmacology, Department of Medicine, European Institute of Oncology, Ripamonti 435, 20141 Milan, Italy. Tel.: +39 02 57489482; fax: +39 0257489457.

E-mail address: gianluca.spitaleri@ieo.it (G. Spitaleri).

1 These authors equally contributed to this work.
}

1040-8428/\$ - see front matter @ 2013 Elsevier Ireland Ltd. All rights reserved. http://dx.doi.org/10.1016/j.critrevonc.2013.06.005 
Methods: We reviewed all the retrospective series reported from 1951 until April 2012. We analyzed cases treated at our institution from 1999 to 2010.

Results: Eighty-three articles (5530 patients; 1956 malignant tumors) were reviewed. Local recurrences were independent of histology. Distant recurrences were more frequent in the malignant tumors (22\%). A total of 172 phyllodes tumors were included in the retrospective analysis.

Discussion: Prognosis of phyllodes tumors is excellent. There are no convincing data to recommend any adjuvant treatment after surgery. Molecular characterization may well provide new clues to permit identification of active treatments for the rare poor prognosis cases.

(C) 2013 Elsevier Ireland Ltd. All rights reserved.

Keywords: Phyllodes tumor; Breast tumors; Literature overview; Retrospective analysis; Prognosis

\section{Introduction}

Phyllodes tumor of the breast are rare neoplasms with an incidence $<1 \%$ of all primary breast tumors [1]. In 1982, the World Health Organization declared the term "phyllodes tumor" as the most appropriate among more than 60 synonyms [2]. After Trevor, Norris and Azzopardi the World Health Organization sub-classified them histologically as benign, borderline, or malignant [3-5]. Benign tumors are more frequent having an incidence of $35-64 \%$ while malignant tumors comprise about $25 \%$ of cases [1,6,7]. The median age of occurrence of disease is $40-50$ years $[1,7,8]$. Histologically, they are fibroepithelial tumors, likely originated from the terminal ducto-lobular unit and considered as stromaderived [5]. Microscopically, the stromal component may be bland resembling that of fibroadenoma, or atypical, resembling that of soft-tissue sarcoma, or it can vary between these extremes, often resembling low-grade sarcoma. Grading is usually based on a semi-quantitative evaluation of the following criteria in the stromal component: nuclear pleomorphism, mitotic rate, overgrowth, cellularity and aspects of tumor margins. Ward firstly reported the presence of stromal overgrowth as putative additional factor of prognosis [9]. In 1991 Cohen-Cedermark included tumor necrosis and the presence of stromal elements other than fibromyxoid tissue among the prognostic factors [10].

Complete surgical resection offers high rates of local control and disease-free survival [1]. Mastectomy has recently been replaced by conservative surgery with adequate negative surgical margins [6,7,11-14]. The potential role of adjuvant radiotherapy is still debated as only a minor fraction of patients have received this treatment and also there is an absence of large prospective trials $[1,12,15-17]$.

We carried out an overview of literature to investigate the prognosis of phyllodes tumor according to tumor grade. We have also included a retrospective analysis of 172 consecutive patients with this tumor from our institute.

\section{Overview of the literature}

\subsection{Methods}

References were obtained from the major indexed literature database Medline, using the keywords breast phyllodes tumor. We reviewed all the cases of breast phyllodes tumors reported from 1951 (after Trevis' publication) until April 2012 [4-84]. We included only the articles in English which focused on clinical reports convincingly documenting the diagnosis, and which clearly reported the treatments administered and follow-up data. The analysis also included four reports written in their original language since their abstract reported all requested information [74-77].

\subsection{Results}

Eighty-three articles were reviewed with a total of 5530 patients (malignant 1956, 35\%). Comprehensively, the mean number of patient per article was 67 (median 37.5; range $1-605)$.

\subsubsection{Description of overall results}

Table 1 reports the most representative studies with about more than 75 patients. These retrospective analyses collected cases treated in a period from 1930 to 2010 . The mean size was $7.3 \mathrm{~cm}$ (median 6.5, range $0.4-29$ ). The mean rate of mastectomies performed was $40 \%$ (range $0-67 \%$ ). The median follow-up was 5 years (range 0.4-43). The mean local recurrence rate was $19.1 \%$ (median $17 \%$; range $0-67 \%$ ). The mean distant recurrence rate was $8.9 \%$ (median 5\%; range 0-39\%). Table 2 summarizes the details of the analysis. Local recurrences were independent of histology, but more frequent in the malignant group. Distant recurrences are almost never encountered in the benign group, whilst they are rare for borderline tumors (except for the report by Reinfuss [7] reporting an incidence of 22\%). The malignant group relapsed with a mean and median rate of almost $25 \%$ (up to $60 \%$ in the 8 cases described by Halverson [24] and in the 13 cases described by Hawkins [43]). In the publications reporting positive surgical margins the mean local recurrence rate reached $31.5 \%$ (median 14.5\%; range 1-67\%) [5-7; 10, 11, 14, 16, 18, 35, $38-40 ; 42-44 ; 48-57 ; 59,60,62-65 ; 67-71 ; 74,75 ; 80-84]$. Fifty-eight progressions (from grade 1 or 2 to upper grade) out of 3574 cases (benign + borderline) were described (1.6\%). Eighteen $(0.3 \%)$ bilateral cases were recorded. A number of reports demonstrated the putative relationship between stromal overgrowth and pathological features (proliferative fraction) or clinical outcome (local and distant relapse, or 
Table 1

Selected retrospective investigations on the management of phyllodes tumors of the breast. Pts = patients; size expressed in cm; $M=$ mastectomy $(\%)$; Mal. = malignant (number); LR locale recurrence $(\%)$; DR distant recurrence $(\%)$; Asia-Austr $=$ Asia-Australia

\begin{tabular}{|c|c|c|c|c|c|c|c|c|c|}
\hline Author & Year & Period & Pts & Country & Size & $M(\%)$ & Mal. & LR & DR \\
\hline Treves & 1951 & 1930-1949 & 77 & USA & 10 & 42 & 18 & 67.0 & 11.6 \\
\hline Norris & 1967 & Before 1967 & 94 & USA & 6.4 & 59 & NR & 35.0 & NR \\
\hline Hajdu & 1976 & $1932-1976$ & 199 & USA & 4 & 23 & 49 & 16.0 & 1.5 \\
\hline Briggs & 1983 & 1960-1980 & 83 & USA & 5 & 12 & 3 & 0.0 & 0.0 \\
\hline Chua & 1988 & 1978-1984 & 106 & Singapore & 5 & 8 & 3 & 19.0 & 0.9 \\
\hline Cohn-Cedermark & 1991 & 1958-1986 & 77 & Swedish & 5 & 69 & 49 & 19.0 & 21.0 \\
\hline Grimes & 1992 & 1983-1990 & 187 & USA & 4.4 & NR & 50 & 28.0 & 8.0 \\
\hline Zurrida & 1992 & 1970-1989 & 216 & Italy & NR & 9 & 14 & 12.5 & NR \\
\hline Reinfuss & 1996 & $1952-1988$ & 170 & Poland & 7 & 42 & 59 & 8.0 & 16.0 \\
\hline Zissis & 1998 & 1981-1995 & 84 & Greece & 6 & 29 & 15 & 2.3 & 1.0 \\
\hline Chaney & 2000 & 1944-1998 & 101 & USA & 6 & 53 & 29 & 4.0 & 8.0 \\
\hline Niezabitowski & 2001 & 1952-1998 & 120 & Poland & NR & 60 & 44 & 8.0 & 9.0 \\
\hline Tse & 2004 & 1988-2001 & 179 & Asia-Austr. & 4.8 & NR & NR & NR & NR \\
\hline Chen & 2005 & 1985-2003 & 172 & Taiwan & 5.8 & 27 & 29 & 11.0 & 1.7 \\
\hline Tan & 2005 & 1992-2002 & 335 & Singapore & 5.4 & 8 & 31 & 12.8 & 2.0 \\
\hline Abdalla & 2006 & 1988-2003 & 79 & Egypt & 11 & 42 & 21 & 20.0 & 14.0 \\
\hline Ben hassouna & 2006 & 1986-2001 & 106 & Tunisia & 8.3 & 23 & 28 & 12.2 & 7.5 \\
\hline Barrio & 2007 & 1954-2005 & 293 & USA & 6 & 16 & 90 & 8.5 & 1.7 \\
\hline Guillot & 2011 & 1994-2008 & 165 & France & 3 & 6 & 14 & 10.0 & 1.2 \\
\hline Pimiento & 2011 & 1999-2010 & 124 & USA & 4.5 & NR & 19 & 6.5 & 1.6 \\
\hline Tan & 2012 & 1992-2010 & 605 & Singapore & 5.2 & 19 & 54 & 11.2 & 1.1 \\
\hline
\end{tabular}

overall survival) $[9-11 ; 40,42,43,49,55,57,59,63,68$, 70].

\subsubsection{Post-surgical treatments}

A total of 278 (14.2\% of malignant cases) patients received complementary radiotherapy. The mean local recurrence rate and the median distant recurrence rate were $9 \%$ (mean $8 \%$, range $0-22 \%$ ) and $13.5 \%$ (mean 16.3 , range $0-38 \%$ ), respectively, in the 6 studies where at least 15 patients (an arbitrary cut-off chosen by the authors) had received radiotherapy $[10,12,15-18 ; 75]$. The median follow-up of these studies was of 13.25 years (mean 16.2, range 4, 6-43). Indeed none of these studies proved that radiotherapy can affect the distant spread of tumor and overall survival. Importantly, Christensen did not reveal any difference in overall

Table 2

Patient demography and clinical outcome according to tumor histology.

\begin{tabular}{ll}
\hline Patients (5530) & \\
\hline Benign & $2861(52 \%)$ \\
Borderline & $713(13 \%)$ \\
Malignant & $1956(35 \%)$ \\
Mean size (range) & $7.3 \mathrm{~cm}(0.4-29)$ \\
Median size & $6.5 \mathrm{~cm}$ \\
Mean rate of mastectomy & $40 \%(0-67 \%)$ \\
The mean local recurrence rate (median, range) & \\
All & $19.1 \%(0-67)$ \\
Benign & $15 \%(12.5,0-42)$ \\
Borderline & $17 \%(19,0-50)$ \\
Malignant & $28 \%(21,0-100)$ \\
The mean distant recurrence rate (median, range) & \\
All & $8.9 \%(0-39 \%)$ \\
Benign & $0.1 \%(0 ; 0-2 \%)$ \\
Borderline & $0.2 \%(0 ; 0-33 \%)$ \\
Malignant & $22 \%(22 ; 0-62.5 \%)$
\end{tabular}

survival between the group who was treated with radiotherapy and the group treated with surgery alone in a retrospective series [15]. In 2009 Barth published the first non-randomized prospective trial of radiotherapy for 46 consecutive patients with malignant tumors and demonstrated that radiotherapy can reduce the local recurrences $(0 \%)$, although there were two distant metastases [17]. Chaney et al. compared in a retrospective series the patients (6) treated with adjuvant radiotherapy with other patients treated with surgery alone (23): the former had a lower risk of local relapse $(9 \%$ at 10 years of follow up) [18]. This data was confirmed by an Indian experience (Pandey et al.) where 25 out of 37 patients received adjuvant radiotherapy. Unfortunately, 20 of the 37 patients had positive/unknown surgical margins and the actuarial local failure was $22 \%$ [16]. In our opinion this study places greater emphasis on the importance of negative margins than on the role of radiotherapy. Overall, only 72 patients were treated with chemotherapy (36 in adjuvant setting). Among the four studies reporting adjuvant chemotherapy the follow-up is too short (mean 2.6; median 2.1; range 1-5.4 years) and indeed there was a higher rate of surgical positive margins $(0.3-39 \%)$ : the distant recurrence rate was not lower relative to the other publications with a range of $1.2-40 \%[53,71,74,80]$. The most significant trial is represented by that by Morales-Vasquez (a non-prospective trial) which demonstrated that the addition of adjuvant chemotherapy (doxorubicin/dacarbazine) to surgery did not reduce the risk of disease recurrence [71].

\subsubsection{Biomarkers involved on tumor progression from fibroadenoma to malignant phyllodes tumor}

Numerous studies (preclinical or retrospective reports) have investigated some biomarkers that can be involved in 
Table 3

Molecular features which were described in tumor progression from benign to malignant tumor and could be putative prognostic factor. EGFR: epidermal growth factor receptor; c-kit: kit oncogene; p16INK4a: cyclin-dependent kinase inhibitor 2A; Wnt5: similar to wingless-type MMTV integration site family, member 5B precursor; pRB: retinoblastoma protein; RASSF1A: Ras association (RalGDS/AF-6) domain family 1 protein; TWIST1: twist homolog 1 (Drosophila); EPS15: EGFR pathway substrate 15; FA: fibroadenoma; PT: phyllodes tumor.

\begin{tabular}{|c|c|c|c|}
\hline Molecule/pathway & Mechanism & Findings & Reference $(\operatorname{Ref} N)$ \\
\hline EGFR amplification & $\begin{array}{l}\text { EGFR/EPS15/caveolin-1 interplay in the } \\
\text { carcinogenesis }\end{array}$ & Preclinical & Agelopoulos '07 [85] \\
\hline \multirow[t]{2}{*}{ EGFR expression } & \multirow[t]{2}{*}{ Progression to borderline/malignant } & Positive & Tse '09 [89] \\
\hline & & Negative & Yonemori '06 [61] \\
\hline \multirow[t]{3}{*}{ C-kit expression } & \multirow[t]{3}{*}{ Progression to borderline/malignant } & Positive & Noronha'11 [93] \\
\hline & & & Esposito '06 [62] \\
\hline & & Negative & Yonemori 2006 [61] \\
\hline C-kit mutations & A 'druggable target' & Negative &  \\
\hline $\begin{array}{l}\text { Increased number of } \\
\text { chromosomal gains (e.g4q12) }\end{array}$ & Progression to borderline/malignant & Positive & Lu '08 [86] \\
\hline $\begin{array}{l}\text { 9p deletion (loss of } \\
\text { p16INK4a) }\end{array}$ & Progression to borderline/malignant & Positive & Jones '08 [87] \\
\hline Wnt5a expression & $\begin{array}{l}\text { Role for progression and epithelial/stromal } \\
\text { interactions }\end{array}$ & Positive & Karim '09 [88] \\
\hline $\begin{array}{l}\text { Stromal p16 and } \\
\text { stromal/epithelial pRb } \\
\text { expression }\end{array}$ & Progression to borderline/malignant & Positive & Karim '10 [90] \\
\hline $\begin{array}{l}\text { Methylation of RASSF1A } \\
\text { and TWIST1 }\end{array}$ & Progression from FA to PT & Positive & Huang '10 [92]; Kwon '11 [94] \\
\hline CD10 expression & Prediction of occurrence of metastasis & Positive & Al-Masri '11 [95] \\
\hline
\end{tabular}

tumor progression from fibroadenoma to malignant phyllodes tumor (Table 3) [61,85-95]. Most were focus on the role of Epidermal Growth Factor Receptor, c-kit and Wnt pathways: unfortunately they produced almost contrasting results.

\section{Retrospective series}

\subsection{Methods}

Data from 172 patients with breast phyllodes tumors (out of 203 patients with all breast sarcomas) [96] treated at the European Institute of Oncology in Milan from 1999 to 2010 were collected retrospectively. Diagnosis was confirmed histologically on the surgical specimens. Stromal overgrowth was defined as an absence of ductal elements in a $40 \times$ low-power field. Follow-up was obtained by internal data base clinical collection and interviews. The principal endpoint was 10-year cumulative incidence of phyllodes-specific events. Disease-related events were defined as: ipsilateral breast recurrence, recurrence in the breast and axilla, and distant metastases. Secondary end-points included 10-year cumulative incidence of specific-phyllodes deaths and overall survival. Cumulative incidences were compared across different subgroups by means of the Gray test [97]. Multivariate Cox proportional hazards regression models were used to identify the prognostic independent clinico-pathological parameters associated with the risk of phyllodes-related events. The variables which showed some statistical significance $(P<0.10)$ in the overall univariate analysis were tested in the multivariable model with a forward selection method.
Adjusted hazard ratios (HR) with $95 \%$ confidence intervals (CIs) were reported. All analyses were carried out with the SAS software (SAS Institute, Cary, NC) and the R software (http://cran.r-project.org/). All the reported $P$-values were two sided.

\subsection{Results}

From 1999 to 2010172 cases with phyllodes tumor were retrieved. Patients treated in our institution (167) and those referred for consultation (5) to our site from other hospitals were included in the analysis (Table 4). There were 68

Table 4

Patient demographics (EIO series).

\begin{tabular}{ll}
\hline Patients $(172)(\%)$ & \\
\hline Age (median years) & 44 \\
Age (range years) & $11-82$ \\
Female/male & $175 / 1$ \\
Histology & \\
Benign phyllodes & $68(39.5)$ \\
Borderline phyllodes & $42(24.5)$ \\
Malignant phyllodes & $62(36)$ \\
Size & \\
$\leq 2 \mathrm{~cm}$ & $19(11.9)$ \\
$2-\leq 5 \mathrm{~cm}$ & $82(51.6)$ \\
$>5 \mathrm{~cm}$ & $58(36.5)$ \\
Not available & 13 \\
Surgery & \\
Mastectomy & $35(20)$ \\
Conservative & $137(80)$ \\
Adjuvant treatments & \\
Chemotherapy & $3(1.7)$ \\
Radiotherapy & $9(5.0)$ \\
\hline
\end{tabular}




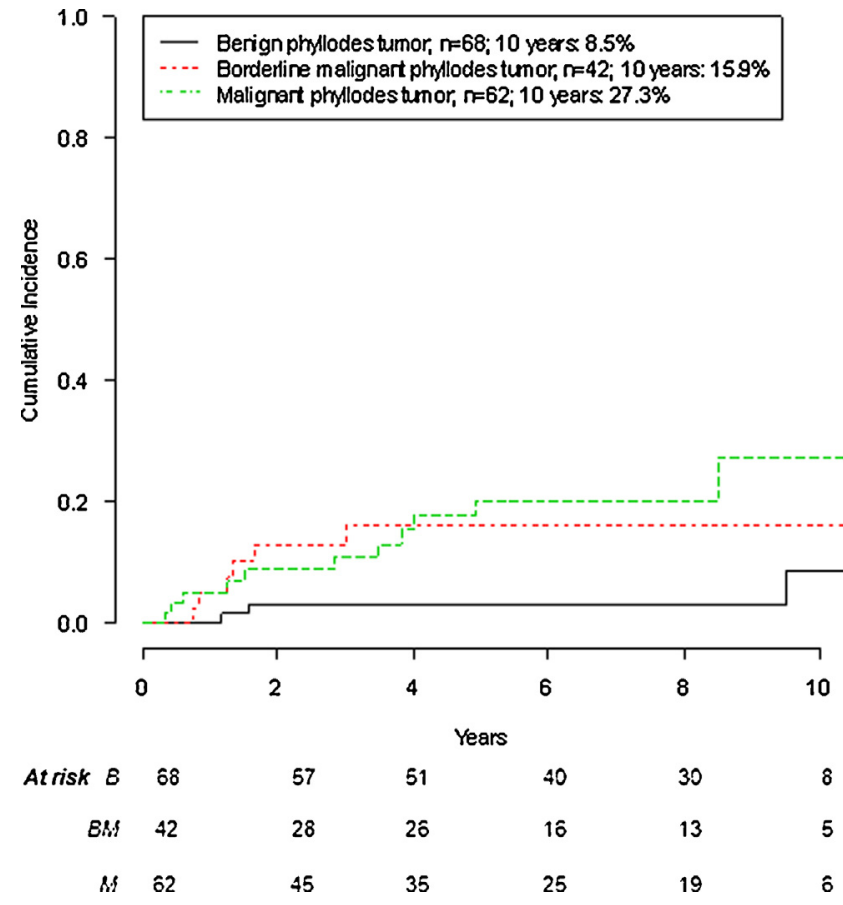

Fig. 1. Cumulative incidence of phyllodes-related events by histotype. Breast-related events: (a) Benign phyllodes tumor group: ipsilateral breast recurrence $(n=3)$; (b) borderline malignant phyllodes tumor group: ipsilateral breast recurrence $(n=6)$; (c) malignant phyllodes tumor group: ipsilateral breast recurrence $(n=8)$, recurrence in the breast and axilla $(n=1)$, distant metastases $(n=2)$.

benign, 42 borderline and 62 malignant phyllodes. Median follow-up was 85 months (4.5-268 months). Most of the patients $(137,80 \%)$ underwent conservative surgery, while 35 (20\%) underwent mastectomy, of which 20 benefited from breast reconstruction. We observed 20 phyllodes-related first events: 17 local recurrences, one chest-wall involvement and two distant events. The 10-year cumulative incidence of phyllodes-related events was $16.6 \%$ (95\% CI 9.7-27.2). Four phyllodes-related deaths and 3 deaths from other causes were observed. The 10-year cumulative incidence of phyllodesrelated deaths was $2.5 \%$ (95\% CI $0.9-6.6 \%)$. The 10 -year overall survival was $94.6 \%$ (95\% CI 88.5-97.5\%).

\subsubsection{Benign tumors}

Figs. 1 and 2 depict the 10-year cumulative incidence of phyllodes-related events according to tumor grade and the 10 -year cancer-specific survival according to tumor grade, respectively. Sixty-eight $(39.5 \%)$ cases out of 172 were benign. All but three of them underwent conservative surgery. We recorded three $(4.5 \%)$ events among these patients and all consisted of local recurrences which were well managed with further surgery. Two patients died from causes unrelated to the tumor.

\subsubsection{Borderline tumors}

Forty-two (24.5\%) patients had a borderline tumor. About $80 \%$ of the patients underwent breast-sparing surgery. We

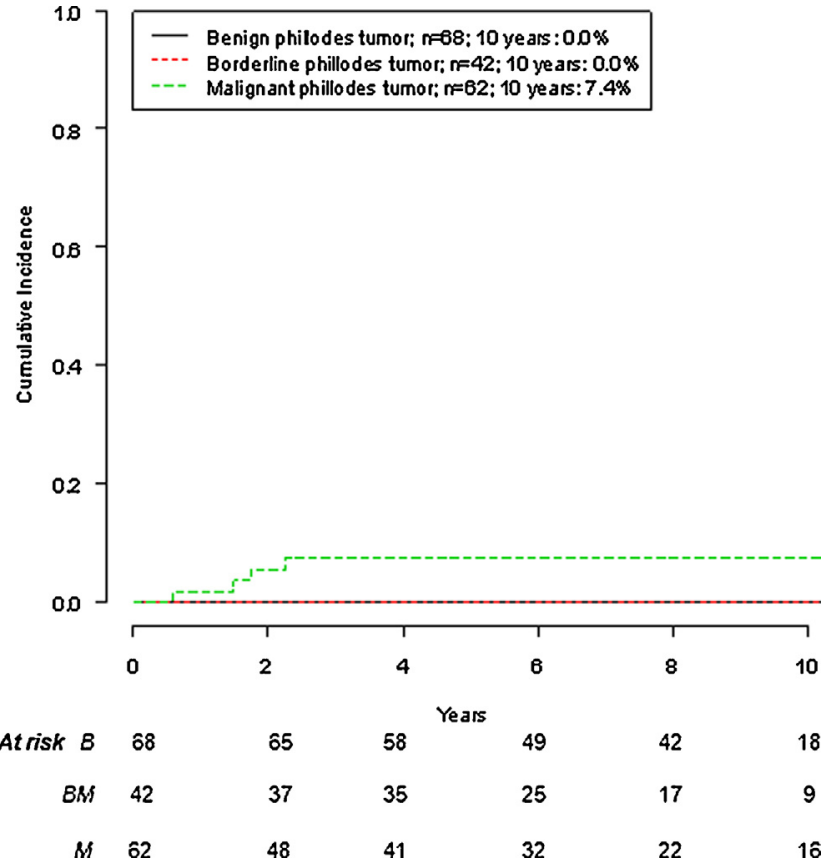

Fig. 2. Cumulative incidence of phyllodes-related deaths by histotype.

recorded $6(14.2 \%)$ events out of these 42 patients and all consisted of local recurrences treated either with conservative surgery or mastectomy. All patients were alive at the analysis cut-off except for one who died from head and neck cancer.

\subsubsection{Malignant tumors}

Sixty-two $(36 \%)$ patients had a malignant phyllodes tumor. Thirty-seven patients $(59.6 \%)$ were treated with a conservative approach. Two patients with malignant phyllodes with unfavorable features received 5 courses of epirubicin/ifosfamide. Eight patients with the same features received radiotherapy after radical surgery. One patient received both chemotherapy and radiotherapy. None of these patients relapsed after a median follow-up of 3.5 years (range $0.5-10)$. Thirteen (21\%) events were recorded in $11(17.7 \%)$ of 62 patients. These consisted of $8(13 \%)$ local recurrences, $1(1.6 \%)$ chest wall infiltration and four (6.5\%) distant metastases. Four patients died from disease progression (3 with a metastatic disease, one for a chest wall infiltration). The 10-year phyllodes-specific survival was $92.6 \%$.

\subsubsection{Uni- and multi-variate analyses}

Univariate analysis (Table 5) identified age as a prognostic factor for all phyllodes-related events, with the risk decreasing with increasing age. The subgroup of malignant tumors showed a similar trend, but the association was not statistically significant. Presence of necrosis, stromal overgrowth and positive surgical margins were putative negative prognostic factors for recurrence in the overall population $(P<0.10)$. Despite the sparse number of events, surgical margin status was a significant prognostic factor in the malignant tumor subgroup. In the multivariable analysis (Table 6), 
Table 5

Uni-variate analysis for phyllodes-related events for all patients and according to tumor grade.

\begin{tabular}{|c|c|c|c|c|c|c|c|c|c|c|c|c|c|}
\hline & & \multicolumn{3}{|l|}{ All } & \multicolumn{3}{|l|}{ Benign } & \multicolumn{3}{|l|}{$\begin{array}{l}\text { Borderline } \\
\text { malignant }\end{array}$} & \multicolumn{3}{|l|}{ Malignant } \\
\hline & & No. $(\%)$ & $\begin{array}{l}\text { Events } \\
\text { (10-year cum } \\
\text { inc\%) }\end{array}$ & & No. $(\%)$ & $\begin{array}{l}\text { Events } \\
\text { (10-year cum } \\
\text { inc\%) }\end{array}$ & & No. $(\%)$ & $\begin{array}{l}\text { Events } \\
(10 \text {-year cum } \\
\text { inc\%) }\end{array}$ & & No. $(\%)$ & $\begin{array}{l}\text { Events } \\
\text { (10-year cum } \\
\text { inc\%) }\end{array}$ & $\mathrm{P}$ \\
\hline \multirow[t]{4}{*}{ Age } & Total & 172 & $20(16.6)$ & & 68 & $3(8.5)$ & & 42 & $6(15.9)$ & & 62 & $11(27.3)$ & \\
\hline & $<35$ & $35(20.4)$ & $9(37.6)$ & 0.01 & $15(22.1)$ & $1(7.7)$ & 0.56 & $8(19.0)$ & $4(50.0)$ & $<0.01$ & $12(19.4)$ & $4(54.5)$ & 0.29 \\
\hline & $35-49$ & $83(48.3)$ & $7(15.5)$ & & $37(54.4)$ & $2(14.6)$ & & $23(54.8)$ & $1(5.0)$ & & $23(37.1)$ & $4(20.0)$ & $0.12^{\mathrm{c}}$ \\
\hline & $\geq 50$ & $54(31.4)$ & $4(8.6)$ & & $16(23.5)$ & $0(0.0)$ & & $11(26.2)$ & $1(9.1)$ & & $27(43.6)$ & $3(14.1)$ & \\
\hline \multirow[t]{3}{*}{ Tumor size $^{\mathrm{a}}$} & $\leq 2 \mathrm{~cm}$ & $20(12.0)$ & $2(20.8)$ & 0.88 & $14(20.6)$ & $2(22.6)$ & 0.25 & $3(7.3)$ & $0(0.0)$ & 0.51 & $3(5.2)$ & $0(0.0)$ & 0.70 \\
\hline & $2.1-5 \mathrm{~cm}$ & $85(50.9)$ & $11(15.0)$ & & $39(57.4)$ & $1(2.9)$ & & $21(51.2)$ & $4(22.2)$ & & $25(43.1)$ & $6(27.6)$ & \\
\hline & $>5 \mathrm{~cm}$ & $62(37.1)$ & $7(18.2)$ & & $15(22.1)$ & $0(0.0)$ & & $17(41.5)$ & $2(13.2)$ & & $30(51.7)$ & $5(35.6)$ & \\
\hline \multirow[t]{2}{*}{ Necrosis ${ }^{a}$} & No & $161(94.2)$ & $16(15.2)$ & 0.09 & $68(100.0)$ & $3(8.5)$ & - & $41(97.6)$ & $6(16.3)$ & 0.67 & $52(85.3)$ & $7(24.9)$ & 0.23 \\
\hline & Yes & $10(5.9)$ & $3(31.7)$ & & $0(0.0)$ & - & & $1(2.4)$ & $0(0.0)$ & & $9(14.7)$ & $3(35.6)$ & \\
\hline \multirow[t]{2}{*}{ Overgrowth $^{\mathrm{a}}$} & No & $104(68.0)$ & $8(11.6)$ & 0.07 & $58(93.6)$ & $3(9.7)$ & 0.74 & $29(80.6)$ & $4(15.3)$ & 0.32 & $17(30.9)$ & $1(7.7)$ & 0.18 \\
\hline & Yes & $49(32.0)$ & $8(26.8)$ & & $4(6.4)$ & $0(0.0)$ & & $7(19.4)$ & $0(0.0)$ & & $38(69.1)$ & $8(34.5)$ & \\
\hline \multirow[t]{2}{*}{ Surgical margins $a, b$} & Negative & $161(94.2)$ & $16(15.1)$ & 0.09 & $67(98.5)$ & $2(7.0)$ & $<0.01$ & $39(95.0)$ & $5(14.5)$ & 0.57 & $55(88.7)$ & $9(28.6)$ & 0.74 \\
\hline & Positive & $10(5.9)$ & $3(30.0)$ & & $1(1.5)$ & $1(100.0)$ & & $2(5.0)$ & $0(0.0)$ & & $7(11.3)$ & $2(28.6)$ & \\
\hline \multirow[t]{2}{*}{ Surgery } & BCS & $137(79.7)$ & $14(14.1)$ & 0.21 & $65(95.6)$ & $3(8.6)$ & 0.75 & $35(88.1)$ & $6(19.5)$ & 0.21 & $37(59.7)$ & $5(17.1)$ & 0.22 \\
\hline & Mastectomy & $35(20.3)$ & $6(28.9)$ & & $3(4.4)$ & $0(0.0)$ & & $7(11.9)$ & $0(0.0)$ & & $25(40.3)$ & $6(43.5)$ & \\
\hline
\end{tabular}

${ }^{a}$ Information was missing for one or more patients.

b Tumor present on the surgical margin $(n=5)$ or within $1 \mathrm{~mm}$ or less from the margin $(n=5)$

${ }^{c}$ Testing the trend. BCS: breast conservative surgery. Breast-related events: (a) benign phyllodes tumor group: ipsilateral breast recurrence ( $\left.n=3\right)$; (b) borderline malignant phyllodes tumor group: ipsilateral breast recurrence $(n=6)$; (c) malignant phyllodes tumor group: ipsilateral breast recurrence $(n=8)$, recurrence in the breast and axilla $(n=1)$, distant metastases $(n=2)$. 
Table 6

Multivariate survival analysis of tumor-related events.

\begin{tabular}{lll}
\hline Parameters & & HR $(95 \%$ C.I. $)$ \\
\hline Age (years) & $<35$ vs $\geq 50$ & $5.4(1.5-19.6)$ \\
& $35-49$ vs $\geq 50$ & $1.5(0.4-5.5)$ \\
Necrosis & Present vs absent & $3.9(1.1-14.1)$ \\
Surgical margins & Positive vs negative & $3.9(1.1-14.3)$ \\
\hline
\end{tabular}

young age $(<35$ years), presence of necrosis and positive surgical margins were associated with a significant increase of risk of phyllodes-related events. When limiting the analysis to borderline and malignant phyllodes, age remained the only significant prognostic factor.

\section{Discussion}

This is an overview of the English literature since 1951 with a total of 5530 patients and a median follow-up of 5 years. This overview is augmented with a presentation of new 172 cases of breast phyllodes treated at our Institution from 1999 to 2010 with a median follow-up of 7 years.

This tumor is clearly more frequent in women: in our series, there was only one case in a man, few cases have been reported in men and these have invariably been associated with gynecomastia $[23,98]$.

Multi-focality (2-5 lumps) has been variably reported in literature where the highest incidence (up to $12 \%$ ) was reported by Ben hassouna [65], whereas bilateral cases are rare being from 0 to $3.5 \%$ [70]. In our series we did not encounter multi-focality or bilateral cases.

Regarding the distribution of histology: benign tumors are more frequent $(52 \%$ in the literature, about $40 \%$ in our series). The risk of local recurrence is irrespective of histology, although the events are more frequent in the malignant and borderline tumors than in benign group. Among the benign and borderline tumors all local relapses can be well managed by further surgery (either breast-conserving surgery or mastectomy). In this group (benign/borderline) positive surgical margins do not seem to predict a worse outcome. Two aspects must be taken in account during the recurrence after resection of benign or borderline tumor: the risk of distant recurrence and the sarcomatous progression (from benign/borderline to malignant tumor). The risk of distant relapse is very low $(<0.5 \%$ in the literature, no events in our series). Tumor progression has been reported with wide range of percent (3-33\%) in different reports with a median of $4 \%$ $[3,4,7,18,20,23,25,27,32,59,65,70]$. The highest incidence of events was reported in a small series [25], whereas the largest series reported a lower incidence $(3 \%)[59,65,70]$. Accordingly, the standard treatment for these tumors is a breast conserving surgery with negative margins. Based on the fact that local recurrences are usually well managed with breast sparing surgery and that the risk of tumor progression is low, a policy of 'wait and see' should be safely considered in cases with positive surgical margins, as already stated by Zurrida [14].
Different aspects are encountered in the malignant group, where there is a higher incidence of local relapse (about 30\% both in the literature and in our series) and there is the chance of distant relapse: in our series we recorded one chest wall involvement and four distant metastases (6.4\%) with four phyllodes-related deaths. In the literature overview the risk of systemic spread for malignant tumors was higher (22\%). In any case, the extent of surgery did not affect long-term survival, so far the main standard of treatment is represented by breast spearing surgery (when feasible according to tumor and breast dimensions) with mandatory surgical negative margins. The role of adjuvant radiotherapy is also a matter of debate. In our series only nine patients received adjuvant radiotherapy and none of them relapsed. In the literature, radiotherapy has been shown to reduce the risk of local but not of distant relapse in malignant tumors. All these reports, however, were retrospective series with the exception of the study by Barth $[10,12,15-18 ; 75]$. At this time, the indication for radiotherapy should be limited to patients with malignant tumors and positive surgical margins when a surgical radicalization cannot be performed.

The role of adjuvant chemotherapy is even more questionable and it is not indicated [71].

Beyond histology, different parameters (clinical or molecular) has been investigated to predict a higher risk of relapse. In our series, according to the multivariable analysis, young age ( $<35$ years), tumor necrosis and positive surgical margins were associated with a significant increase of phyllodesrelated events. Many reports dealt with young age as a putative prognostic factor [4,20-22,33,99]. Except for the report by Chua [34], all other studies identified young age as a favorable prognostic factor contrary to our data.

In the near future, the molecular characterization of these unusual breast tumors might well allow the identification of high risk tumors for distant relapse. Numerous studies have attempted to determine whether immunohistochemical markers may be useful to predict the clinical outcome of the patients, but so far all these markers have failed to attain any clinical validation [61,85-95]. It would be also extremely important to identify 'druggable targets' for this type of tumor, that it is notably chemorefractory.

In conclusion, we confirm that the prognosis of benign and borderline phyllodes tumors is excellent. They are cured with surgery alone. Most, but not all malignant phyllodes tumors also have a good prognosis. The main standard of treatment is adequate surgery with negative margins. No convincing data are available to suggest any adjuvant treatment. For the rare poor prognosis tumors in the near future molecular characterization may well provide new clues to permit identification of more active treatments.

\section{Conflict of interest disclosure}

None. 


\section{Reviewers}

Dr. Jasdeep Gahir, Division of Breast Surgery, St. Bartholomew's Hospital, West Smithfield, London, United Kingdom.

Dr. Pierre-Alain Brioschi, Head of Gyneco-Oncology and Senology, Clinique de Genolier, 1, route du Muids, CH-1272 Genolier, Switzerland.

\section{Acknowledgement}

The authors thank Mr. William Russell-Edu for help with the English.

\section{References}

[1] Macdonald OK, Lee CM, Tward JD, et al. Malignant phyllodes tumor of the female breast: association of primary therapy with cause-specific survival from the Surveillance, Epidemiology, and End Results (SEER) program. Cancer 2006;107(9):2127-33.

[2] The World Health Organization. The World Health Organization histological typing of breast tumors - second edition. The World Organization. American Journal of Clinical Pathology 1982;78:806-916.

[3] Azzopardi JG. Sarcoma in the breast. In: Azzopardi JG, editor. Problems in breast pathology. Philadelphia: WB Saunders; 1979. p. 346-65.

[4] Treves N, Sunderland DA. Cystosarcoma phyllodes of the breast: a malignant and a benign tumor; a clinicopathological study of seventyseven cases. Cancer 1951;4(6):1286-332.

[5] Norris HJ, Taylor HB. Relationship of histologic features to behavior of cystosarcoma phyllodes analysis of ninety-four cases. Cancer 1967;20(12):2090-9.

[6] Pietruszka M, Barnes L. Cystosarcoma phyllodes: a clinicopathologic analysis of 42 cases. Cancer 1978;41(5):1974-83.

[7] Reinfuss M, Mitus J, Duka K, Stelmach A, Rys J, Smolak K. The treatment and prognosis of patients with phylloides tumor of the breast: an analysis of 170 cases. Cancer 1996;77(5):910-6.

[8] Salvadori B, Cusumano F, Del Bo R, et al. Surgical treatment of phyllodes tumors of the breast. Cancer 1989;63(12):2532-6.

[9] Ward RM, Evans HL. Cystosarcoma phyllodes: a clinicopathologic study of 26 cases. Cancer 1986;58(10):2282-9.

[10] Cohn-Cedermark G, Rutqvist LE, Rosendahl I, et al. Prognostic factors in cystosarcoma phyllodes. A clinicopathologic study of 77 patients. Cancer 1991;68(9):2017-22.

[11] Moffat CJ, Pinder SE, Dixon AR, et al. Phyllodes tumours of the breast: a clinicopathological review of thirty-two cases. Histopathology 1995;27(3):205-18.

[12] Soumarova R, Seneklova Z, Horova H, et al. Retrospective analysis of 25 women with malignant cystosarcoma phyllodes-treatment results. Archives of Gynecology and Obstetrics 2004;269(4):278-81.

[13] Staren ED, Lynch G, Boyle C, Witt TR, Bines SD. Malignant cystosarcoma phyllodes. The American Surgeon 1994;60(8):583-5.

[14] Zurrida S, Bartoli C, Galimberti V, et al. Which therapy for unexpected phyllode tumor of the breast? European Journal of Cancer 1992;28(2/3):654-7.

[15] Christensen L, Schiødt T, Blichert-Toft M, et al. Sarcomas of the breast: a clinico-pathological study of 67 patients with long term follow-up. European Journal of Surgical Oncology 1988;14(3):241-7.

[16] Pandey M, Mathew A, Kattoor J, et al. Malignant phyllodes tumor. The Breast Journal 2001;7(6):411-6.
[17] Barth Jr RJ, Wells WA, Mitchell SE, Cole BF. A prospective, multiinstitutional study of adjuvant radiotherapy after resection of malignant phyllodes tumors. Annals of Surgical Oncology 2009;16(8):2288-94.

[18] Chaeny AW, Pollack A, McNeese MD, et al. Primary treatment of cystosarcoma phyillodes of the breast. Cancer 2000;89(7):1502-11.

[19] Zissis C, Apostolikas N, Konstantinidou A, Griniatsos J, Vassilopoulos PP. The extent of surgery and prognosis of patients with phyllodes tumor of the breast. Breast Cancer Research and Treatment 1998;48(3):205-10.

[20] Lester J, Stout AP. Cystosarcoma phyllodes. Cancer 1954;7(2):335-53.

[21] McDivitt RW, Urban JA, Farrow JH. Cystosarcoma phyllodes. The Johns Hopkins Medical Journal 1967;120(1):33-45.

[22] Amerson JR. Cystosarcoma phyllodes in adolescent females. A report of seven patients. Annals of Surgery 1970;171(6):849-56.

[23] West TL, Weiland LH, Clagett T. Cystosarcoma phyllodes. Annals of Surgery 1971;173(4):520-8.

[24] Halverson JD, Hori-Rubaina JM. Cystosarcoma phyllodes of the breast. The American Surgeon 1974;40(5):295-301.

[25] Blichert-Toft M, Hansen JP, Hansen OH, Schiodt T. Clinical course of cystosarcoma phyllodes related to histologic appearance. Surgery, Gynecology \& Obstetrics 1975;140(6):929-32.

[26] Hoover HC, Trestioreanu A, Ketcham AS. Metastatic cystosarcoma phylloides in an adolescent girl: an unusually malignant tumor. Annals of Surgery 1975;181(3):279-82.

[27] Hajdu SI, Espinosa MH, Robbins GF. Recurrent cystosarcoma phyllodes a clinicopathologic study of 32 cases. Cancer 1976;38(3):1402-6.

[28] Andersson A, Bergdahl L. Cystosarcoma phyllodes in young women. Archives of Surgery 1978;113(6):742-4.

[29] Schmidt B, Lantsberg L, Goldstein J, Khodadadi J. Cystosarcoma phyllodes. Israel Journal of Medical Sciences 1981;17(9/10):895-8.

[30] Contarini O, Urdaneta LF, Hagan W, Stephenson Jr SE. Cystosarcoma phylloides of the breast: a new therapeutic proposal. The American Surgeon 1982;48(4):157-66.

[31] Grigioni WF, Santini D, Grassigli A, et al. A clinico-pathologic study of cystosarcoma phyllodes, twenty cases report. Archives D'anatomie et de Cytologie Pathologiques 1982;30(5/6):303-6.

[32] Lindquist KD, van Heerden JA, Weiland LH, Martin Jr JK. Recurrent and metastatic cystosarcoma phyllodes. American Journal of Surgery 1982;144(3):341-3

[33] Briggs RM, Walters M, Rosenthal D. Cystosarcoma phylloides in adolescent female patients. American Journal of Surgery 1983;146(6):712-4.

[34] Chua CL, Thomas A. Cystosarcoma phyllodes tumors. Surgery, Gynecology \& Obstetrics 1988;166(4):302-6.

[35] Hart J, Layfield LJ, Trumbull WE, et al. Practical aspects in the diagnosis and management of cystosarcoma phyllodes. Archives of Surgery 1988;123(9):1079-83.

[36] Inoshita S. Phyllodes tumor (cystosarcoma phyllodes) of the breast. A clinicopathologic study of 45 cases. Acta Pathologica Japonica 1988;38(1):21-33.

[37] Murad TM, Hines JR, Beal J, Bauer K. Histopathological and clinical correlations of cystosarcoma phyllodes. Archives of Pathology \& Laboratory Medicine 1988;112(7):752-6.

[38] Kario K, Maeda S, Mizuno Y, et al. Phyllodes tumor of the breast: a clinicopathologic study of 34 cases. Journal of Surgical Oncology 1990;45(1):46-51.

[39] Keelan PA, Myers JL, Wold LE, et al. Phyllodes tumor: clinicopathologic review of 60 patients and flow cytometric analysis in 30 patients. Human Pathology 1992;23(9):1048-54.

[40] Bennett IC, Khan A, De Freitas R, et al. Phyllodes tumours: a clinicopathological review of 30 cases. The Australian and New Zealand Journal of Surgery 1992;62(8):628-33.

[41] Ciatto S, Bonardi R, Cataliotti L, Cardona G. Phyllodes tumor of the breast: a multicenter series of 59 cases. Coordinating Center and Writing Committee of FONCAM (National Task Force for Breast Cancer), Italy. European Journal of Surgical Oncology 1992;18(6): $545-9$. 
[42] Grimes MM. Cystosarcoma phyllodes of the breast: hystologic features, flow cytometric analysis, and clinical correlations. Modern Pathology 1992;5(3):232-9.

[43] Hawkins RE, Schofield JB, Fisher C, et al. The clinical and histologic criteria that predict metastases from cystosarcoma phyllodes. Cancer 1992;69(1):141-7.

[44] Rowell MD, Perry RR, Hsiu JG, Barranco SC. Phyllodes tumors. American Journal of Surgery 1993;165(3):376-9.

[45] Modena S, Prati G, Mainente M, et al. Phyllodes tumor of the breast: problems of differential diagnosis and therapeutic approach from an analysis of 17 cases. European Journal of Surgical Oncology 1993;19(1):70-3.

[46] Hopkins ML, McGowan TS, Rawlings G, et al. Phylloides tumor of the breast: a report of 14 cases. Journal of Surgical Oncology 1994;56(2):108-12.

[47] Iau PT, Lim TC, Png DJ, Tan WT. Phyllodes tumour: an update of 40 cases. Annals of the Academy of Medicine, Singapore 1998;27(2):200-3.

[48] de Roos WK, Kaye P, Dent DM. Factors leading to local recurrence or death after surgical resection of phyllodes tumor of the breast. British Journal of Surgery 1999;86(3):396-9.

[49] Feakins RM, Mulcahy HE, Nickols CD, Wells CA. p53 expression in phyllodes tumours is associated with histological features of malignancy but does not predict outcome. Histopathology 1999;35(2):162-9.

[50] Holthouse DJ, Smith PA, Naunton-Morgan R, Minchin D. Cystosarcoma phyllodes: the western Australian experience. The Australian and New Zealand Journal of Surgery 1999;69(9):635-8.

[51] Mangi AA, Smith BL, Gadd MA, et al. Surgical management of phyllodes tumors. Archives of Surgery 1999;134(5):487-92.

[52] Niezabitowski A, Lackowska B, Rys J, et al. Prognostic evaluation of proliferative activity and DNA content in the phyllodes tumor of the breast: immunohistochemical and flow cytometric study of 118 cases. Breast Cancer Research and Treatment 2001;65(1):77-85.

[53] Kok K, Telesinghe P, Yapp S. Treatment and outcome of Cystosarcoma phyllodes in Brunei: a 13 year experience. Journal of the Royal College of Surgeons of Edinburgh 2001;46(4):198-201.

[54] Kapiris I, Nasiri N, A'Hern R, et al. Outcome and predictive factors of local recurrence and distant metastases following primary surgical treatment of high-grade malignant phyllodes tumours of the breast. European Journal of Surgical Oncology 2001;27(8):723-30.

[55] Shpitz B, Bomstein Y, Sternberg A, et al. Immunoreactivity of p53, $\mathrm{Ki}-67$, and c-erbB-2 in phyllodes tumors of the breast in correlation with clinical and morphologic features. Journal of Surgical Oncology 2002;79(2):86-92.

[56] Joshi SC, Sharma DN, Bahadur AK, et al. Cystosarcoma phyllodes: our institutional experience. Australasian Radiology 2003;47(4):434-7.

[57] Eroglu E, Irkkan C, Ozsoy M, Eroglu F. Phyllodes tumor of the breast: case series of 40 patients. European Journal of Gynaecological Oncology 2004;25(1):123-5.

[58] Tse GMK, Lui PCW, Lee CS, et al. Stromal expression of vascular endothelial growth factor correlates with tumor grade and microvessel density in mammary phyllodes tumors: a multicenter study of 185 cases. Human Pathology 2004;35(9):1053-7.

[59] Chen WH, Cheng SP, Tzen CY, et al. Surgical treatment of phyllodes tumors of the breast: retrospective review of 172 cases. Journal of Surgical Oncology 2005;91(3):185-94.

[60] Tan PH, Jayabaskar T, Chuah KL, et al. Phyllodes tumors of the breast: the role of pathologic parameters. American Journal of Clinical Pathology 2005;123(4):529-40.

[61] Yonemori K, Hasegawa T, Shimizu C, et al. Correlation of p53 and MIB1 expression with both the systemic recurrence and survival in cases of phyllodes tumors of the breast. Pathology, Research and Practice 2006;202(10):705-12.

[62] Esposito NN, Mohan D, Brufsky A, et al. Phyllodes tumor a clinicopathologic and immunohistochemical study of 30 cases. Archives of Pathology \& Laboratory Medicine 2006;130(10):1516-21.
[63] Fou A, Schnabel FR, Hamele-Bena D, et al. Long-term outcomes of malignant phyllodes tumors patients: an institutional experience. American Journal of Surgery 2006;192(4):492-5.

[64] Abdalla HM, Sakr MA. Predictive factors of local recurrence and survival following primary surgical treatment of phyllodes tumors of the breast. Journal of the Egyptian National Cancer Institute 2006;18(2):125-33.

[65] Ben hassouna J, Damak T, Gamoudi A, et al. Phyllodes tumors of the breast: a case series of 106 patients. American Journal of Surgery 2006;192(2):141-7.

[66] Confavreux C, Lurkina A, Mitton N, et al. Sarcomas and malignant phyllodes tumours of the breast - A retrospective study. European Journal of Cancer 2006;42(16):2715-21.

[67] Fajdić J, Gotovac N, Hrgović Z, et al. Phyllodes tumors of the breast diagnostic and therapeutic dilemmas. Onkologie 2007;30(3):113-8.

[68] Taira N, Takabatake D, Aogi K, et al. Phyllodes tumor of the breast: stromal overgrowth and histological classification are useful prognosispredictive factors for local recurrence in patients with a positive surgical margin. Japanese Journal of Clinical Oncology 2007;37(10):730-6.

[69] Lenhard MS, Kahlert S, Himsl I, et al. Phyllodes tumour of the breast: clinical follow-up of 33 cases of this rare disease. European Journal of Obstetrics, Gynecology, and Reproductive Biology 2008;138(2):217-21.

[70] Barrio AV, Clark BD, Goldberg JI, et al. Clinicopathologic features and long-term outcomes of 293 phyllodes tumors of the breast. Annals of Surgical Oncology 2007;14(10):2961-70.

[71] Morales-Vasquez F, Gonzalez-Angulo AM, Broglio K, et al. Adjuvant chemotherapy with doxorubicin and dacarbazine has no effect in recurrence-free survival of malignant phyllodes tumors of the breast. The Breast Journal 2007;13(6):551-6.

[72] Bhargav PRK, Mishra A, Agarwal G, et al. Phyllodes tumour of the breast: clinicopathological analysis of recurrent vs. non-recurrent cases. Asian Journal of Surgery 2009;32(4):224-8.

[73] Karim RZ, Gerega SK, Yang YH, et al. Phyllodes tumours of the breast: a clinicopathological analysis of 65 cases from a single institution. Breast 2009;18(3):165-70.

[74] Haberer S, Laéb M, Seegers V, et al. Management of malignant phyllodes tumors of the breast: the experience of the Institut Curie. Cancer Radiotherapie 2009;13(4):305-12 (Article in French).

[75] Bouhafa T, Masbaha O, Bekkouch I, et al. Phyllodes tumors of the breast: analysis of 53 patients. Cancer Radiotherapie 2009;13(1):85-91 (Article in French).

[76] Fang Y, Gao JD, Tian YT, et al. Analysis of the treatment and prognosis of recurrent breast phyllodes tumor. Zhonghua Zhong Liu Za Zhi 2009;31(1):72-4 (Article in Chinese).

[77] Sakurai K, Enomoto K, Amano S, et al. Long-term results of surgical therapy for phyllodes tumor of the breast. Gan To Kagaku Ryoho 2010;37(12):2784-5 (Article in Japanese).

[78] Akin M, Irkorucu O, Koksal H, et al. Phyllodes tumor of the breast; a case series. Bratislavske Lekarske Listy 2010;111(5):271-4.

[79] Verma S, Singh RK, Rai A, et al. Extent of surgery in the management of phyllodes tumor of the breast: a retrospective multicenter study from India. Journal of Cancer Research and Therapy 2010;6(4):511-5.

[80] Guillot E, Couturaud B, Reyal F, et al. Management of phyllodes breast tumors. The Breast Journal 2011;17(2):129-37.

[81] Schwentner L, Kurzeder C, Kreienberg R, Wöckel A. Focus on haematogenous dissemination of the malignant cystosarcoma phylloides: institutional experience. Archives of Gynecology and Obstetrics 2011;283(3):591-6.

[82] Abe M, Miyata S, Nishimura S, et al. Malignant transformation of breast fibroadenoma to malignant phyllodes tumor: long-term outcome of 36 malignant phyllodes tumors. Breast Cancer 2011;18(4): $268-72$.

[83] Pimiento JM, Gadgil PV, Santillan AA, et al. Phyllodes tumors: racerelated differences. Journal of the American College of Surgeons 2011;213(4):537-42. 
[84] Tan PH, Thike AA, Tan WJ, et al. Predicting clinical behaviour of breast phyllodes tumours: a nomogram based on histological criteria and surgical margins. Journal of Clinical Pathology 2012;65(1):69-76.

[85] Agelopoulos K, Kersting C, Korsching E, et al. Egfr amplification specific gene expression in phyllodes tumours of the breast. Cellular Oncology 2007;29(6):443-51.

[86] Lu S, Niu Y, Wei L, et al. Chromosomal aberrations and genetic relations in benign, borderline and malignant phyllodes tumors of the breast: a comparative genomic hybridization study. Breast Cancer Research and Treatment 2008;112(3):411-8.

[87] Jones AM, Mitter R, Springall R, et al. A comprehensive genetic profile of phyllodes tumours of the breast detects important mutations, intratumoral genetic heterogeneity and new genetic changes on recurrence. Pathology 2008;214(5):533-44.

[88] Karim RZ, Scolyer RA, Tse GM, et al. Pathogenic mechanisms in the initiation and progression of mammary phyllodes tumours. Pathology 2009;41(2):105-17.

[89] Tse GM, Lui PC, Vong JS, et al. Increased epidermal growth factor receptor (EGFR) expression in malignant mammary phyllodes tumors. Breast Cancer Research and Treatment 2009;114(3):441-8.

[90] Karim RZ, Gerega SK, Yang YH. el. p16 and pRb immunohistochemical expression increases with increasing tumour grade in mammary phyllodes tumours. Histopathology 2010;56(7):868-75.

[91] Bose P, Dunn ST, Yang J, et al. c-Kit expression and mutations in phyllodes tumors of the breast. Anticancer Research 2010;30(11):4731-6.

[92] Huang KT, Dobrovic A, Yan M, et al. DNA methylation profiling of phyllodes and fibroadenoma tumours of the breast. Breast Cancer Research and Treatment 2010;124(2):555-65.

[93] Noronha Y, Raza A, Hutchins B, et al. CD34, CD117, and Ki-67 expression in phyllodes tumor of the breast: an immunohistochemical study of 33 cases. International Journal of Surgical Pathology 2011;19(2):152-8.

[94] Kwon JE, Jung WH, Koo JS. Molecules involved in epithelialmesenchymal transition and epithelial-stromal interaction in phyllodes tumors: implications for histologic grade and prognosis. Tumour Biology 2012;33(3):787-98.
[95] Al-Masri M, Darwazeh G, Sawalhi S, et al. Phyllodes tumor of the breast: role of CD10 in predicting metastasis. Annals of Surgical Oncology 2012;19(4):1181-4.

[96] Toesca A, Spitaleri G, De Pas T, et al. Sarcoma of the breast: outcome and reconstructive options. Clinical Breast Cancer 2012;12(6):438-44.

[97] Gray RJ. A class of k-sample tests for comparing the cumulative incidence of a competing risk. Annals of Statistics 1988;16:1141-54.

[98] Pantoja E, Llobet RE, Lopez E. Gigantic cystosarcoma phyllodes in a man with gynecomastia. Archives of Surgery 1976;111:611.

[99] Maisels DO. Giant fibroadenoma of the breast in young women. Journal of The Royal Colleges of Surgeons of Edinburgh 1980;25(4):242-5.

\section{Biographies}

Gianluca Spitaleri is a Consultant of Thoracic and Soft Tissue Sarcoma Unit at the European Institute of Oncology. Major areas of interest of his lung cancer-research and rare tumors. He published more than 20 scientific publications on international peer-reviewed journals.

Antonio Toesca is a Consultant of the Division of Breast Surgery at the European Institute of Oncology. Major areas of interest of his breast carcinoma and breast non-carcinoma subtypes. He is an Author and Co-Author of significant scientific publications on international peer-reviewed journals.

Tommaso De Pas is the Director of the Thoracic and Soft Tissue Sarcoma Unit and is a Member of the Board for the Italian Sarcoma Group as well. Major areas of interest of his lung cancer-research and rare tumors. He published about 100 scientific publications on international peer-reviewed journals. 